\title{
Fostering Generalist Leaders in a Subspecialized World: Congratulations to an Expanded Cohort of New Pisacano Scholars
}

\author{
Andrew W. Bazemore, MD, MPH, Jane Ireland, Robert Cattoi, and \\ Warren P. Newton, MD, MPH
}

(J Am Board Fam Med 2022;35:210-213.)

"The challenge we all face is how to maintain the benefits of breadth, diverse experience, interdisciplinary thinking, and delayed concentration in a world that increasingly incentivizes, even demands, hyperspecialization"

- David Epstein, "Range: How Generalists Triumph in a Specialized World"1

As health systems grow in number and complexity, so do their associated leadership roles. And this growing array of opportunities to direct increasingly intricate clinical practice groups, public health systems, academic departments, research enterprises and policy begs for generalists trained to first diagnose problems faced before seeking and applying solutions. Breadth of training and the variety of experience begets competency in facing the unknown and undifferentiated and is the wellspring of innovation. Family physicians receive the broadest training of all physician specialties, and their care remains the most complex by many measures. ${ }^{2-5}$

The American Board of Family Medicine (ABFM) has proudly supported leadership and scholarship development in Family Medicine for decades, ${ }^{6}$ across a host of programs and investments, including

- Pisacano Scholars Leadership Program

- James C Puffer Fellowship at the National Academy of Medicine

This article was externally peer reviewed.

Submitted 12 November 2021.

From the Center for Professionalism \& Value in Health Care, The American Board of Family Medicine, Washington, DC (AWB); The American Board of Family Medicine, Lexington, KY 40511 (JI, RC, WPN).

Funding: none.

Corresponding author: Andrew Bazemore, MD, MPH, Center for Professionalism \& Value in Health Care, The American Board of Family Medicine, 1016 16th Street NW, Washington, DC 20036 (E-mail: abazemore@theabfm.org).
- Visiting Scholars programs in Lexington, KY and Washington, DC

- Center for Professiox nalism \& Value and its Fellowship program

- The Montegut Scholars program

The flagship Pisacano Scholar program was created in 1990 to identify and promote leadership development in our discipline and has evolved into 1 of the pre-eminent leadership programs available to trainees of any background. Since 1993, the PLF has annually selected outstanding medical students who have been identified as the future leaders in the field of Family Medicine. Pisacano Scholars receive scholarships, educational opportunities, and leadership training over a 4-year period, before becoming part of an alumni group who form a community of lifelong learners in family medicine leadership. Their thought leadership has influenced countless crucial conversations for the discipline ${ }^{7-9}$ and their leadership span a range of settings from the primary care safety net to academia to "C Suites" in integrated health systems. Recognizing the increasing need for family physician leaders across many different missions, the ABFM announced in 2021 its commitment to double the size of the program for at least 5 years selecting up to 10 (vs the traditional 5) scholars per class. The Pisacano Leadership Foundation Board of Directors additionally declared its intent to continue to enhance its applicant pool and process, in the interest of selecting a more diverse group of scholars from a broader range of medical schools. The 2021 class of scholars is the largest since the beginning of the program, when 10 scholars were selected for the first 2 classes. 


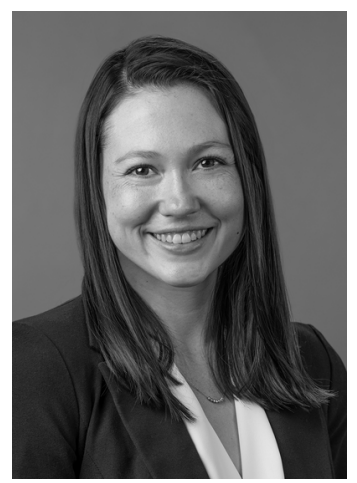

Katie Brown (University of Cincinnati College of Medicine/The Ohio State University)

Katie grew up watching her father and grandfather - both family physicians who accepted eggs and oil changes as payment - build trusting relationships with their patients that spanned generations. Like them, she reaches to her Haudenosaunee roots for strength and guidance, striving to become a healer who serves her community. She looks forward to practicing full-spectrum Family Medicine with a focus on underserved and global health.

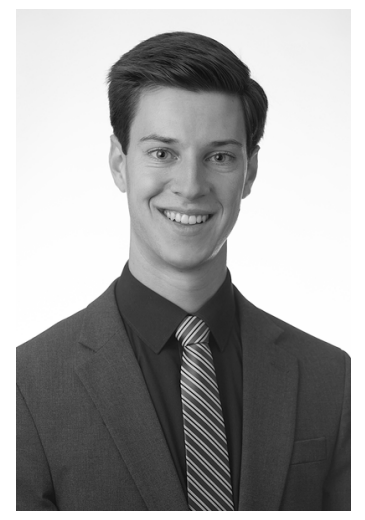

Preston Butler (Boston University School of Medicine/University of Texas at Dallas)

Preston plans to dedicate his career in Family Medicine to supporting the health of medically under-resourced communities. He seeks to practice full-spectrum care with emphasis in maternal and child health and Lesbian, Gay, Bisexual, Transgender, and Queer (LGBTQ) health, promoting interdisciplinary practice, equity, and antiracism among other focuses.

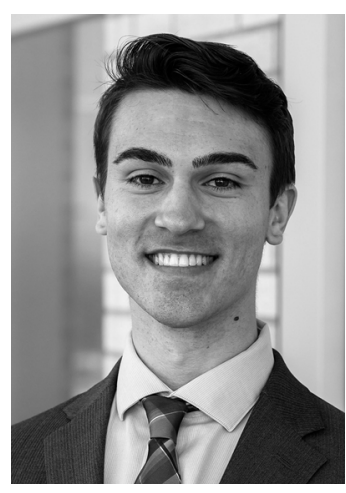

Jordan Gemelas (Oregon Health and Science University/University of Washington)

During his career, Jordan hopes to explore the full breadth of family medicine as much as possible, with plans to work as a broad scope provider in rural, urban underserved, academic, and community settings. Ultimately, he aims to leverage his public health and clinical training to advance the health of populations through research, teaching, leadership, policy, and direct medical care.

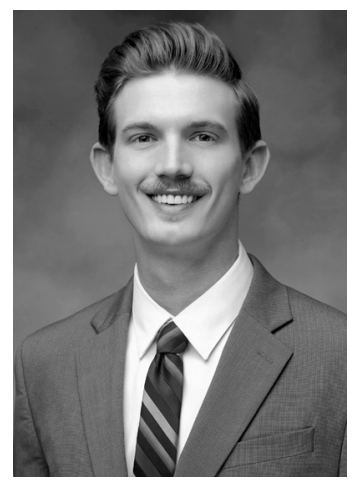

Garrett S. Kneese (University of Texas Health San Antonio Long School of Medicine/University of Texas at San Antonio)

Following his training, Garrett looks forward to a multi-endeavored career balancing community-oriented primary care, population health programming, teaching of the next generation of family doctors and leadership in the specialty of family medicine that he holds dear. 


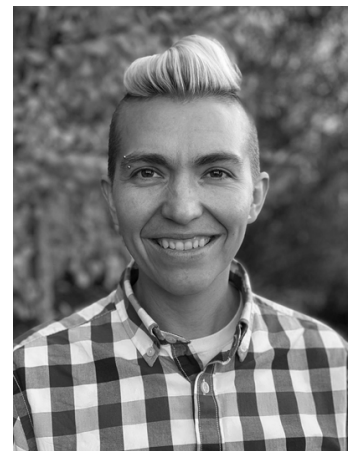

Emiliano Lemus Hufstedler, MS (University of California [UC]-Berkeley-UC San Francisco Joint Medical Program/Harvard College)

Emiliano looks forward to practicing community-based integrative primary care for the LGBTQ community, as well as for BIPOC (Black, Indigenous and people of color) and Spanish-speaking Latinx immigrant communities. As a lifelong community organizer, Emiliano is excited to continue advocating for the health of their communities via activism and research on structural determinants of health.

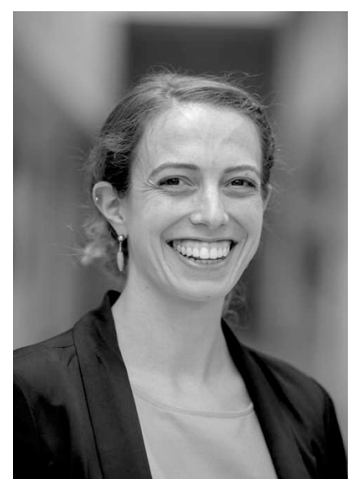

Jessica Meyer (University of Rochester School of Medicine and Dentistry/Colorado College)

During medical school Jessica sought out a broad range of experiences to learn innovative and nontraditional models of primary care to increase health equity via clinical care, advocacy, and research. In her future career, Jessica plans to focus on the areas of reproductive health and addiction medicine and identifying solutions to better care for marginalized patients through advocacy and mixed-methods research.

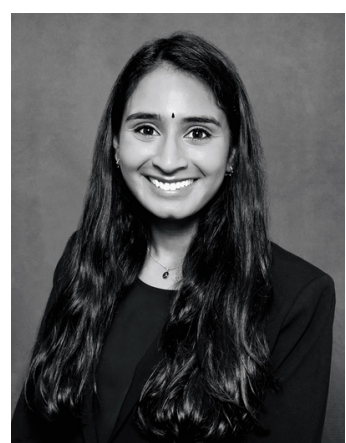

Abhinaya Narayanan (David Geffen School of Medicine at UC Los Angeles/UC-Berkeley)

Abhinaya ultimately hopes to work in the public safety net, caring for historically marginalized and underserved communities while advocating for her patients inside and outside the clinic. She aspires to be a family physician who provides excellent full-spectrum medical care to directly address health disparities, supports social movements that challenge injustices, and leverages her policy training and experience to help build medical systems and a society that protects the health, dignity, and well-being of all.

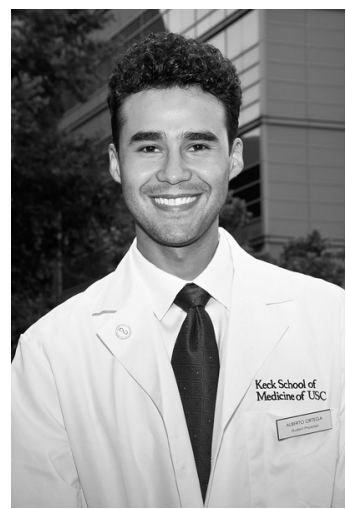

Alberto Ortega (Keck School of Medicine of the University of Southern California/University of Southern California)

As a future family physician, Alberto aspires to serve disenfranchised patients of all ages by improving access to health care, delivering personalized care, and championing disease prevention. He envisions having a rewarding career in which he longitudinally helps patients be proactive about their wellness instead of being reactive to disease. 


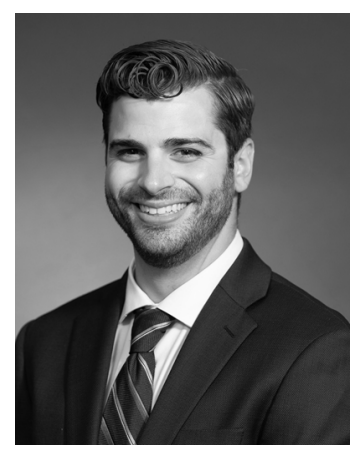

John Romano (University of Massachusetts Chan Medical School/College of Holy Cross)

As a family physician, John seeks to make roots in a rural, underserved community so that he can deeply understand the unique health needs of a population that lacks access to high-quality preventive medicine and unify local resources to provide comprehensive care.

Epstein notes in Range the risk of overspecialization, and even the negative unintended consequences of highly competent specialists all taking independently reasonable courses of action absent broad thinking and coordination. The ABFM is proud to continue to support a new generation of generalist leaders capable of adapting to the complex needs of patients, communities, and health systems if they are to achieve an equally complex Quintuple Aim for American health care - excellent patient experience and population health at lower costs, while preserving clinician wellness and achieving equity. Fully articulating the incredible achievements of these scholars is impossible in the space allotted, but we encourage you to better acquaint yourself with these new scholars and the program itself by visiting the Pisacano Leadership Foundation (http://www.pisacano.org/scholars/current.html). A few minutes on that page will reassure you that the future of Family Medicine is bright. Congratulations
Pisacano Scholars - the leadership challenges ahead are many, but your achievements to date and training to come leave us confident that you are up to the task.

To see this article online, please go to: bttp://jabfm.org/content/ 35/1/210.full.

\section{References}

1. Epstein D. Range: How Generalists Triumph in a Specialized World. Riverhead Books, 2019.

2. Katerndahl D, Providing complex (rather than complicated) chronic care. J Am Board Fam Med 2014;27:6-7.

3. Katerndahl D. Wood DR, Jaén CR. Complexity of ambulatory care across disciplines. Healthc (Amst) 2015;3:89-96.

4. Sharma M, Cheng A, Moore N, Coffman MM, Bazemore AW. Patients with high-cost chronic conditions rely heavily on primary care physicians. J Am Board Fam Med 2014;27.

5. Moore Gibbons M, Cheng C, Coffman N, Petterson MS, Bazemore A. Complexity of ambulatory care visits of patients with diabetes as reflected by diagnoses per visit. Prim Care Diabetes 2016;10:281-6.

6. Bazemore A, Ireland W, Cattoi JR, Newton WP. Shaping keystones in a time of transformation: ABFM's efforts to advance leadership \& scholarship in family medicine. J Am Board Fam Med 2020; 33:156-9.

7. Doohan N, Duane C, Harrison M, Lesko BS, DeVoe JE. the future of family medicine version 2.0: reflections from Pisacano scholars. J Am Board Fam Med 2014;27:142-50.

8. Park B, Coutinho AJ, Doohan N, et al. revisiting primary care's critical role in achieving health equity: Pisacano scholars' reflections from Starfield Summit II. J Am Board Fam Med 2018;31:292302.

9. American Board of Family Medicine. A Paradox Persists When the Paradigm Is Wrong': Pisacano Scholars' Reflections from the Inaugural Starfield Summit | American Board of Family Medicine. Available at: https://www.jabfm.org/content/29/6/793. long. Accessed November 3, 2021. 